\title{
Effect of Election Day Vote Centers on Voter Participation
}

\author{
Robert M. Stein and Greg Vonnahme
}

\begin{abstract}
In this article we study the effects of Election Day vote centers on voter turnout. Specifically we examine Texas and Colorado's experience with alternative arrangements for the number and location of Election Day voting places and its impact on voter turnout in the 2006 and 2008 elections. We test our hypotheses at both the aggregate (i.e., county) and individual levels. We find evidence that vote centers increase voter turnout in presidential and midterm elections, and particularly among infrequent voters in midterms.
\end{abstract}

\section{INTRODUCTION}

$\mathbf{H}$ OW ELECTIONS ARE CONDUCTED, where, when, and how voters are allowed to cast their ballots on and before Election Day, has garnered increasing attention from those studying election performance, specifically turnout. Though the study of election administration is not a new topic (Gosnell 1927; Merriam and Gosnell 1924; Asher 1982), it has gained greater significance in explaining an array of important behaviors and attitudes among the electorate. Ansolabehere and Stewart (2005) were among the first to detect the empirical importance of "institutions of electoral administration, such as the administration of local polling places (2005:386)" to explain the incidence of voter undercounts, i.e., when voters fail to register a preference for an office on the ballot. Stein et al. (2008) and others (Stein and Vonnahme 2008; Brady and McNulty 2011; Gimpel and Schuknecht 2003; Haspel and Knotts 2005; Dyck and Gimbel 2005; Alvarez and Hall 2006; Atkeson and Saunders 2007; Hall, Monson, and Patterson 2009) have demonstrated that the

Robert Stein is the Lena Guhlman Fox professor in the Department of Political Science at Rice University, Houston, TX. Greg Vonnahme is an assistant professor in the Department of Political Science at the University of Alabama, Tuscaloosa, AL. The authors wish to acknowledge the generous support of the Pew Charitable Trusts. location of voting places, the performance of poll workers, and the type of balloting machines used to vote all have significant and independent effects on voter performance including turnout and affect towards the voting experience. Affect towards the voting experience may determine future voter participation (Bendor, Diermeier, and Ting 2003; Fowler 2006) and mode of voting, e.g., voting in-person on or before Election Day and absentee by mail.

In this article we study the effects of Election Day vote centers (EDVC) on voter turnout. Election Day vote centers are polling locations that are open to all voters in a county rather than geographically restricted precincts. Specifically, we examine Texas and Colorado's experience with alternative arrangements for EDVCs and their impact on voter turnout in the 2006 and 2008 elections. We test our hypotheses at both the aggregate (i.e., county) and individual levels. We find that EDVCs increase voter turnout, particularly among infrequent voters. We build on previous research (Stein and Vonnahme 2008; Juenke and Shepherd 2008) by demonstrating that vote centers continue to have a positive impact on voter turnout, especially among habitual nonvoters. Moreover, we detect an emergent property of vote centers: their positive effect on turnout is greater in lower turnout elections and particularly among traditionally non-voting populations.

Our article proceeds with a review of recent research on electoral administration and voter 
turnout, a discussion of vote centers and their attributes that might positively impact voter turnout, a research design for testing our hypotheses, and empirical findings. We conclude with a discussion of the findings and directions for future research.

\section{PREVIOUS RESEARCH}

A host of scholars have examined the effects of polling locations on electoral participation. One recent area of research is the effect of distance between a voter's residence and their polling location on voter turnout. The expectation is that the distance between a voter's residence and polling place is negatively related to their probability of voting (Brady and McNulty 2011) and may be mediated by factors such as access to transportation (Haspel and Knotts 2005) and travel times (Gimpel and Schuknecht 2003).

Factors related to the convenience of voting have also been studied by researchers but, until recently, the effects of convenience on the probability that an individual will vote has not been theoretically well understood. The problem with earlier theoretical models of voter turnout is that they consistently under-predict observed levels of voter turnout. Recent refinements that incorporate a learning process have been shown to better match observed levels of voter turnout in U.S. elections (Bendor, Diermeier, and Ting 2003; Fowler 2006). There is some disagreement as to the specific learning mechanism that voters might use, but these recent models all suggest that voters condition their future voting behavior on their previous experiences. According to these models, if an individual has a positive voting experience in one election, she is more likely to vote in the following election (Fowler 2006; Gerber, Green, and Shachar 2003). Some research also suggests that negative experiences can lead individuals to be less likely to vote in subsequent elections (Fowler 2006). Simply stated, voting, like many other behaviors, is habit forming if it is positively reinforced.

Existing theoretical models of voter turnout provide a basis for linking the convenience of voting to turnout. They also imply that even after the reform is implemented, its full effect might not be immediately realized. The recency (i.e., post 2000) of several electoral reforms (e.g., vote centers, improved poll worker training, and new voting devices) does not provide a source of data to examine long-term effects of the reform, but it might be an important topic for future research. Consequently, we might observe a significant but not full turnout effect of vote centers due to its recent adoption.

Several studies of convenience voting also suggest that the effect varies by the type of election. In particular, election reforms such as vote by mail seem to have a greater impact on otherwise lower turnout elections such as local elections (Magleby 1987; Karp and Banducci 2000; Kousser and Mullin 2007).

\section{Election Day vote centers}

Beginning in 2003, Larimer County, Colorado replaced precinct-based polling places with Election Day vote centers (Stein and Vonnahme 2008). By 2006, 19 Colorado counties had adopted vote centers for Election Day balloting and several other states had passed legislation allowing their counties to adopt or pilot vote centers for the 2008 election.

What are Election Day vote centers? Most generally, they are an alternative means of administering Election Day voting using non-precinct-based polling locations. Traditional precinct-based voting has a large number of relatively small-sized voting places located in residential areas where only certain voters-those who live near the voting precinct-can vote. With Election Day vote centers there are a smaller number of larger-sized voting places, centrally located to major population centers where any voter can vote.

Election Day vote centers typically rely on countywide voter registration databases accessed electronically at each polling site. Voters in the voting jurisdiction (usually a county) are provided ballots appropriate to their voter registration address.

Election Day vote centers mark a different approach to administering Election Day voting. While previous studies of voter turnout have focused on the time it takes to vote as a main obstacle of voting, voting is not necessarily the only thing that individuals have to do on Election Day. In that way, there is an opportunity cost to voting such that voting takes time away from other activities such as work, lunch, shopping, or recreation (Stein and Vonnahme 2008). While voting can be thought of as competing with other activities, voting can also be made more compatible so that all modes of voting will not be equally costly. Focusing on the opportunity costs of voting 
suggests that there might be alternative ways of administering elections that do not eliminate time costs, but rather makes the act of voting more complementary with other demands on voters' time.

As described in previous research, there are two main characteristics of vote centers that allow us to conceptually differentiate vote centers from precinct-based models of election administration. Those two characteristics are openness and centralization (Stein and Vonnahme 2008). Openness refers to the property of vote centers that allow individuals to vote at any location throughout the county rather than be assigned to a particular polling location based on their residential address. Openness might increase turnout by lowering transportation and information costs as voters can go to any location that is most familiar and convenient for them, particularly for individuals traveling outside the home (e.g., commuting for work, school, shopping, or recreation) on Election Day (Stein and Vonnahme 2008).

The second characteristic of vote centers is centralization. Centralization refers to polling locations that are fewer in number and located at larger and more visible sites. Centralization also exists to varying degrees in precinct based polling locations. Centralization may have several positive effects on voter participation (Stein and Vonnahme 2008). Larger and more visible sites can reduce informational costs that voters incur when attempting to find a polling location and offer more available parking at the site. Centralization also allows for better equipped polling locations to efficiently process voters. With more staff at each polling location, poll workers will be able to specialize in certain tasks such as checking in voters or assisting them with their ballots, which should lead to more efficient operations and improved service to voters.

The explanation for why vote centers positively influence voter participation focuses on how this electoral innovation makes voting complementary with other daily and routine activities, a condition that has not been observed with other electoral reforms (e.g., in-person early voting, relaxed voter registration requirements/deadlines, and relaxed mail-in voting). It may seem contradictory to expect voter participation to increase when jurisdictions reduce the number of polling places. A reduction in the number of voting places, along with allowing voters to vote at any location is also accompanied by a significant change in the location, staffing, and equipping of Election Day voting places. A smaller number of larger voting places centrally located to where voters, work, shop, and travel on Election Day, with a larger number of poll workers, parking places, and voting machines lessens the likelihood that voting on a Tuesday will conflict with other daily activities. The proper configuration and location of EDVCs may even complement these nonvoting activities (e.g., shopping at a supermarket with a vote center). It is the size and location of EDVCs that make these voting places more convenient to voters and positively effect voter turnout. ${ }^{1}$

Stein and Vonnahme (2008) found that Election Day vote centers in Larimer County, Colorado had a positive and substantial effect on individual electoral participation, although results from their sensitivity analysis suggested that alternative explanations could not be definitively ruled out. Additionally, the relationship was greater for infrequent rather than frequent voters. The subsequent spread of EDVCs and use in more recent elections not only enables us to further examine the empirical effects of EDVCs but also permits an evaluation across counties, states, and types of elections.

Juenke and Shepherd's (2008) county-level analysis of the turnout effects of vote centers fails to detect a significant positive relationship between the use of vote centers and voter turnout. Moreover, the authors identify a negative, albeit weak and nonrobust, effect for vote centers on turnout in the 2006 mid-term congressional election. They conclude "the new thing in Election Day voting appears to be a lot like every other procedure change before it. It is different, unique, and convenient, but at the end of the day it appears to do little to change the size and makeup of the voting population (2008:63)." The authors suggest that newness of this electoral reform requires further analysis to tease out the joint effects of mobilization and vote centers in altering voting behavior and test for any demographic changes to the voting population. To this conclusion we add one additional caveat. The length of time vote centers have been in operation, especially among the 15 counties that adopted this electoral reform for the first time in 2006, may

\footnotetext{
${ }^{1}$ The inadequate implementation of voter centers can produce congestion at polling places and longer waiting times to vote, both resulting in a strong deterrent to voting. Such was the case in Collin County, Texas in 2010 (Collin County Observer 2011).
} 
have been inadequate for testing the efficacy of this reform on voter turnout. The following section analyzes data from counties in Colorado and Texas from the 2006 and 2008 elections to assess the effect on turnout, particularly among infrequent voters.

\section{DESCRIPTION OF EDVCS}

We collected detailed information on EDVCs as implemented in the 2008 election. While EDVC counties share common characteristics as discussed above, there are variations in the way the reform is implemented. Polling locations must be suitably located and equipped for the geographic and population characteristics of the particular county. We examined several aspects of how EDVCs are implemented in different counties. Table 1 shows a breakdown of the number of registered voters, the number of EDVCs, and the ratio of voters to EDVCs for each of the counties with EDVCs in Colorado for the 2008 election.

As shown in Table 1, there is considerable variation in the number of polling locations and the number of voters per place. There are several factors that might account for this variation. First, the relevant comparison might not be the number of active registered voters per EDVC. That is, some counties have higher rates of early voting and permanent absentee ballot voters which reduce the number of in-person Election Day voters. While a county

Table 1. Descriptive Characteristics of EDVCs in Colorado in the 2008 Election

\begin{tabular}{lccc}
\hline County & EDVCs & $\begin{array}{c}\text { Active Registered } \\
\text { Voters }\end{array}$ & $\begin{array}{c}\text { Voters } \\
\text { per EDVC }\end{array}$ \\
\hline Lake & 2 & 3570 & 1785 \\
Gilpin & 4 & 3678 & 919 \\
Conejos & 8 & 4406 & 551 \\
Moffat & 4 & 6712 & 1678 \\
Archuleta & 3 & 7559 & 2520 \\
Otero & 10 & 9128 & 913 \\
Park & 8 & 10230 & 1279 \\
Chaffee & 5 & 10715 & 2143 \\
Morgan & 6 & 11619 & 1936 \\
Teller & 6 & 13748 & 2291 \\
Summit & 17 & 17138 & 1008 \\
Broomfield & 8 & 31606 & 3951 \\
Mesa & 24 & 76943 & 3206 \\
Weld & 30 & 117046 & 3902 \\
Adams & 40 & 177547 & 4439 \\
Larimer & 24 & 181864 & 7578 \\
\hline
\end{tabular}

might have a higher ratio of voters per polling place, that does not necessarily mean that the locations are serving more voters on Election Day. A second factor is the population density of the county. A densely populated county might be able to concentrate Election Day operations with a smaller number of polling locations whereas a less densely populated county might need additional sites.

To assess the locations of vote centers we geocoded the polling locations in Colorado and Lubbock, Texas counties. To examine distances between EDVCs and voters' residences we geocoded a random sample of 5,000 Election Day voters in Lubbock County and calculated Euclidean distances to each polling location for each voter. Similar data on geographic distances have been previously analyzed (e.g., Gimpel and Schuknecht 2003; Brady and McNulty 2011; Haspel and Knotts 2005) but these data are unique in that vote centers are not geographically designated. This has two related consequences. First, any individual can vote at any polling location so there is not one distance, but rather $\mathrm{k}$ distances where $\mathrm{k}$ is the number of vote centers. Second, residential distance might not be the most relevant quantity as individuals could vote closer to a workplace, travel route, school, or other destination point. Using the geographic information, two quantities were obtained for each individual: the minimum residential distance and the actual residential distance. The minimum residential distance is the distance between a person's residence and the nearest vote center. The actual residential distance is the distance between a person's residence and the polling place where they actually voted. By comparing these two quantities we can assess how far vote centers are from a person's residence, and whether they choose to vote near their residence when given a choice to vote elsewhere.

The results from this analysis show that $36.7 \%$ of the sample voted at the polling location nearest to their house, which leaves a substantial majority that did not vote at the location with the minimum residential distance. The median of the actual residential distance was 1.25 miles while the median of the minimum residential distance was .495 miles. From these data, most individuals appear to vote relatively close to their residence although not necessarily at the location closest to their residence. While this suggests that many 
individuals will vote somewhat farther away when given a choice of where to vote, it should be pointed out that precinct polling locations are not necessarily the closest polling place for voters. If a precinct is irregularly shaped, or if an individual lives near the boundary, she could be closer to a different precinct location, which suggests that, for some voters, the openness of EDVCs reduces residential distance.

\section{EDVCS AND TURNOUT}

In this section, we consider whether EDVCs increased voter turnout in the 2006 and 2008 elections as suggested by research on previous elections. The first source of data that we consider are election returns from Colorado counties from the November 2008 election. A variable for the type of voting system used in each county (EDVC or precinct) was coded from information from the Colorado Secretary of State's office. The dependent variable in these analyses is county turnout, which is measured as the ratio of ballots cast to the number of active registered voters. We use the ratio of registered voters as EDVCs are expected to make voting more convenient, but do not directly affect the registration process. Information on turnout and voter registration was obtained from the Secretary of State's Office. $^{2}$

To analyze these data, we estimate a differencein-difference regression model (Angrist and Pischke 2008). The dependent variable in this analysis is turnout in 2004 and 2008. The interaction between the vote center variable and the 2008 dummy variable shows the effect of vote centers on turnout. We utilize this design to account for both electionspecific effects (e.g., turnout was slightly lower in all counties in 2008) and county-specific effects (e.g. certain counties might have persistently higher or lower turnout). For example, counties with a larger population likely have higher rates of mobility which is related to lower voter turnout (Highton 2000). Of particular concern is the possibility that counties with higher turnout are more likely to adopt EDVCs. The regression estimates shown in Table 2 suggest that EDVCs increase turnout $(b=0.024)$ but the estimate is not significant at conventional levels $(\mathrm{p}=0.175)$. While the results are not statistically significant, the samples for these analyses are also fairly small $(n=126)$. Although vote centers were most
Table 2. Difference-In-Difference Regression ESTIMATES

\begin{tabular}{lcc}
\hline & $2004-2008$ & $2002-2006$ \\
\hline Year & -0.006 & 0.104 \\
& $(0.504)$ & $(0.000)$ \\
EDVC County & {$[-0.010,0.017]$} & {$[0.078,0.130]$} \\
& -0.015 & -0.076 \\
& $(0.236)$ & $(0.000)$ \\
Year $\times$ EDVC & {$[-0.036,0.006]$} & {$[-0.109,-0.042]$} \\
& 0.024 & 0.044 \\
Intercept & $(0.175)$ & $(0.127)$ \\
& {$[-0.005,0.054]$} & {$[-0.004,0.092]$} \\
& 0.889 & 0.583 \\
$\mathrm{~N}$ & {$[0.000)$} & $(0.000)$ \\
\hline
\end{tabular}

$P$-values from a two-tailed test are shown in parentheses. $90 \%$ confidence intervals are shown in brackets.

widely used in Colorado, Lubbock County in Texas also used EDVCs in the November 2008 elections. Comparing turnout in Lubbock County to statewide turnout suggests a similar effect as turnout increased statewide by $1.8 \%$ over 2004, and by $4.7 \%$ in Lubbock County (difference of $2.9 \%$ ).

Two limitations of these analyses are that they do not account for individual factors that also affect turnout and do not allow us to assess whether the effect varies by individual characteristics such as prior voting history. To account for characteristics of individual voters we also analyzed the voter data file from Colorado. The Colorado voter file provides validated turnout data for all registered voters in the state of Colorado. It also provides a measure of voters' age, major party registration status, sex, and prior voting history. Prior voting history includes all general, primary, and local elections from 1996. This information is used to create a count of the number of elections in which each person voted.

To control for these factors we match individuals in EDVC counties to individuals that were in traditional precinct counties. This was done by first selecting a random sample of 10,000 individuals in EDVC counties and 60,000 potential controls in

\footnotetext{
${ }^{2}$ One potential concern with this analysis is that if EDVCs actually had a negative effect on turnout the reform could depress the number of active registered voters and potentially increase the turnout rate by shrinking the pool of registered voters. This appears not to occur, as Larimer County, which has had the longest experience with EDVCs, had a $16 \%$ increase in active registered voters from 2004 to 2008 while the statewide increase was $10 \%$.
} 
precinct counties. Observations in EDVC counties were exactly matched to a corresponding control on the observed control variables (age, sex, major party registration, and prior vote history). Of the initial 10,000 observations, 9,776 were exactly matched to a control, for a $97.8 \%$ match rate. Since the observations are exactly matched on the observable characteristics, the samples are balanced on these variables.

Table 3 shows logit estimates of turnout from the matched sample of 2008 Colorado voters. ${ }^{3}$ These results show that EDVCs have a positive and significant effect on turnout, and that this effect is fairly consistent for frequent and infrequent voters. To assess the substantive effect of EDVCs, Figure 1 shows the effect of EDVCs on the probability of voting. As shown in the figure, the effect is positive and slightly higher for individuals with a low to moderate amount of prior voting experience.

We also analyzed a matched sample from Lubbock, Potter, and Randall counties in Texas. Unfortunately, we were not able to match on sex as this information is not included in the Randall voter file. The prior vote history was also not as extensive in Texas, as the information spanned general, primary, and local elections from 2004. We matched observations exactly on the remaining variables (age, major party registration, and prior vote history). Of the initial random sample of 10,000 Lubbock voters, we successfully matched $99.3 \%$

Table 3. Logit Estimates of 2008 Turnout

\begin{tabular}{lcc}
\hline & $C O$ & $T X$ \\
\hline EDVC & $0.109 * *$ & $0.850 * * *$ \\
Age & $(0.044)$ & $(0.045)$ \\
& 0.001 & $-0.003 * * *$ \\
Female & $(0.001)$ & $(0.001)$ \\
& $0.214 * * *$ & \\
Major party & $(0.034)$ & \\
& $0.322^{* * *}$ & $0.591 * * *$ \\
Vote History & $(0.035)$ & $(0.079)$ \\
& $0.179 * * *$ & $0.172 * * *$ \\
EDVC $\times$ Vote History & $(0.009)$ & $(0.011)$ \\
& 0.003 & $0.050 * * *$ \\
Constant & $(0.013)$ & $(0.014)$ \\
& 0.067 & 0.064 \\
Observations & $(0.059)$ & $(0.049)$ \\
& 19,552 & 19,884 \\
\hline
\end{tabular}

Robust standard errors in parentheses. $* * * p<0.01, * * p<0.05, * p<0.1$.

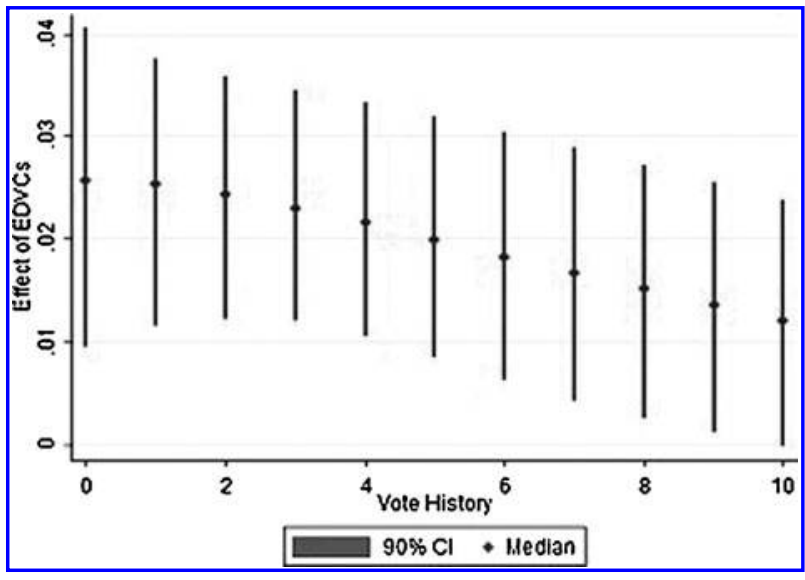

FIG. 1. Effect of EDVCs on the probability of voting (CO 2008).

to a corresponding control. As shown in the third column in Table 3, the results from this analysis are consistent with the findings from Colorado, as EDVCs have a positive and significant effect on turnout. As before, the coefficients cannot be interpreted as marginal effects so we calculated predicted probabilities shown in Figure 2. The results in Figure 2 show that the effect is somewhat greater for individuals with a low to moderate amount of previous voting experience.

One notable difference between the two states is that vote centers appear more efficacious in the analysis of Texas counties than in Colorado. There are several possible explanations for the difference in the size of the effect. One is that turnout was higher in Colorado so there is a ceiling to the effect of any reform in presidential elections in Colorado. Since there was relatively lower turnout and campaign activity in Texas, there was a greater opportunity for the reform to increase turnout. It is also possible that the reform was implemented more effectively in Texas, and there is the possibility that unobserved differences (other than EDVCs and the control variables) are influencing turnout in the Colorado counties, Texas counties, or both. Additionally, Lubbock has a large population of

\footnotetext{
${ }^{3} \mathrm{We}$ also conducted placebo tests in which we regressed turnout in 2004 on EDVCs. As anticipated, the placebo-vote centers have a weaker effect on turnout than the actual vote centers. In the case of Texas, the placebo-vote centers were associated with a reduction in turnout. The Appendix provides a discussion of the placebo test, model estimates, and limitations of the analyses.
} 


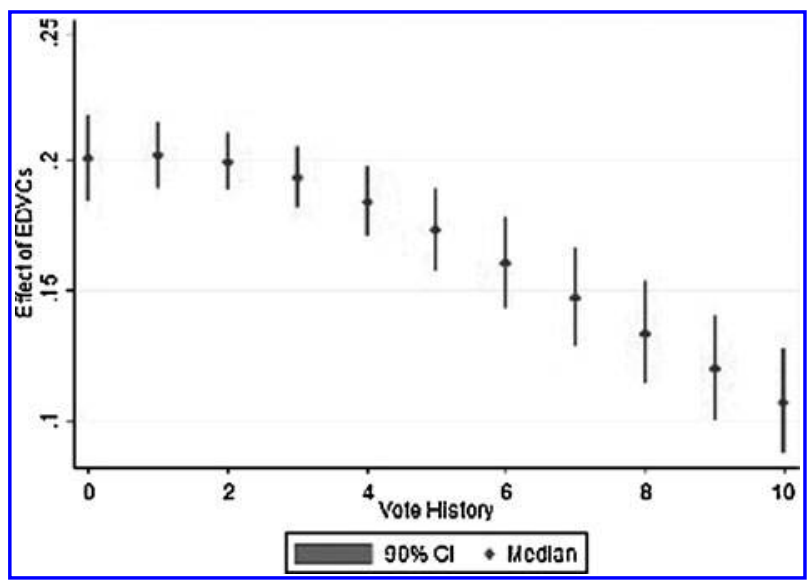

FIG. 2. Effect of EDVCs on the probability of voting (TX 2008).

college students (Texas Tech University) that might be especially responsive to EDVCs.

Additional analyses were conducted using data from the 2006 midterm elections. As discussed above, previous studies have found that election reforms tend to have a greater effect in lower turnout elections. The methods of analysis for the 2006 data are the same as those reported above.

Data were collected for the November 2002 and November 2006 elections for each county in Colorado from the Secretary of State's office. Turnout rates were calculated as the ratio of ballots cast for the top of the ticket race (the governor's race had the highest turnout in 2002 and 2006) to the number of active registered voters. Next, we regressed the turnout rate on the EDVC variable, the year variable $(1=2006$, $0=2002$ ) and the interaction. The interaction represents the effect of EDVCs accounting for election-specific and county-specific factors. The results show that turnout went up in Colorado from 2002 to 2006 and particularly for EDVC counties $(b=0.044, p=0.127)$. While the estimate is not statistically significant at conventional levels, the sample size is also relatively small. Looking at Texas, turnout in Lubbock County remained relatively unchanged. Turnout decreased by $3.7 \%$ and by $4.4 \%$ in Lubbock for a net decrease of $0.7 \%$.

An analysis of voter file data was also conducted. For this analysis, control variables were created for age, gender, party registration, and vote history. Individuals in EDVC counties were then exactly
Table 4. Logit Estimates of 2006 Turnout

\begin{tabular}{lc}
\hline & Coefficient \\
\hline EDVC & $0.209^{* * *}$ \\
Age & $(0.048)$ \\
& $0.012^{* * *}$ \\
Female & $(0.001)$ \\
& -0.034 \\
Major party & $(0.034)$ \\
& $0.226^{* * *}$ \\
Vote History & $(0.036)$ \\
& $0.304^{* * *}$ \\
EDVC $\times$ Vote History & $(0.011)$ \\
& $-0.064^{* * *}$ \\
Denver/Douglas & $(0.013)$ \\
& $-0.374^{* * *}$ \\
Constant & $(0.049)$ \\
& $-1.839^{* * *}$ \\
Observations & $(0.061)$ \\
\end{tabular}

Robust standard errors in parentheses. $* * * p<0.01, * * p<0.05, * p<0.1$.

matched on these characteristics to corresponding individuals in precinct counties. The matching was conducted by first randomly selecting a pool of 10,000 treated observations and a pool of 60,000 potential controls. This provided a successful match rate of $98.2 \%$. Logit estimates are shown in Table 4. The model also includes a control variable for Denver and Douglas counties. This was done to account for the extraordinary circumstances of the election, as these two counties experienced failures of newly adopted pollbook software that caused voters at some polling locations to wait in line for hours on Election Day. ${ }^{4}$ From this table, we can see that EDVCs appear to increase turnout, particularly for less frequent voters. Figure 3 shows the substantive effect of EDVCs on turnout.

Our findings tentatively point to a positive turnout effect of vote centers. This finding, however, varies by type of election. In lower turnout and presumably less salient elections (e.g., 2006 midterm election), vote centers have a significant and pronounced effect on voter turnout, particularly among less frequent voters. In contrast, vote centers have a similar effect on voter turnout for frequent and infrequent voters in high turnout elections

\footnotetext{
${ }^{4}$ See: Merrit, 2006.
} 


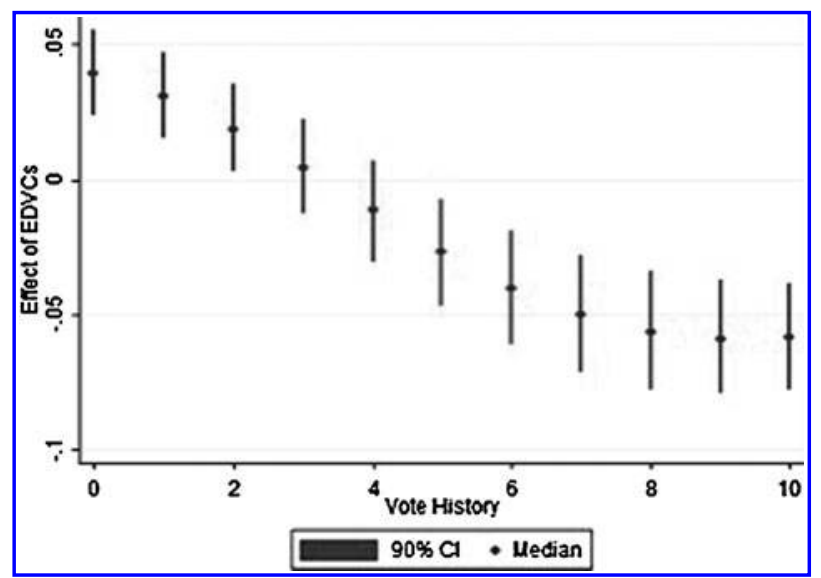

FIG. 3. Effect of EDVCs on the probability of voting (CO 2006).

(e.g., 2008 presidential election). This result is similar to the effect of absentee mail-in voting which also varies by the type of election (Magleby 1987; Karp and Banducci 2000; Kouser and Mullin 2007). ${ }^{5}$

\section{CONCLUSION}

The results from our research suggest that EDVCs increase voter turnout, which is consistent with previous research on early adopters of vote centers (Stein and Vonnahme 2008). More importantly, we have shown that the positive effect vote centers have on voter turnout is enduring and extends to a wider set of counties and states than those that first adopted this electoral reform in 2003. One unanticipated finding is the much stronger and positive effect vote centers have on voter turnout among non-habitual voters in low (i.e., 2006) than higher turnout elections (i.e., 2008). Though this is not an altogether unexpected finding, it underscores the concern that other factors rival the effects of electoral reforms like vote centers.

This finding might be expected. Lower turnout midterm congressional elections do not generate as much campaign activity as do high turnout presidential elections. The positive effect vote centers have on voter participation, in addition to the publicity generated by local election officials, is more likely to be muted in higher volume presidential elections than in lower volume non-presidential elections. Consequently, whatever effect vote centers have on the likelihood that infrequent voters will vote might be muted by the significantly greater volume and effect of a presidential election. Conversely, absent the mobilizing effect of a presidential election, the convenience of vote centers has a less impeded effect on mobilizing infrequent voters in quiescent elections. There is supporting evidence for this assessment. Arceneaux and Nickerson (2009) and Malhotra et al. (2011) report that efforts to mobilize low propensity voters is significantly greater in high rather than low turnout elections.

There remain several other important questions about vote centers that require further investigation and which inform our understanding about the administration of elections. What are the costs of voting and how might vote centers and other administrative reforms help contain these costs? Do vote centers provide a more positive experience for the voter, increasing the likelihood, ceteris paribus, that a voter will vote in successive elections?

Elections are costly, and not just for the candidates who contest for public office. With the adoption of the Help America Vote Act in 2004 election officials are now required to comply with a host of costly regulations and requirements including new voting equipment, provisional voting, assistance for other abled persons, and other minimum administration standards. New voting machines purchased in 2001 with federal funding have reached or exceeded their reliable usefulness and their replacement is not likely to be funded with new federal moneys. Consequently, the savings that might accrue from vote centers' greater efficiency may not be inconsequential.

Vote centers are expected to reduce the inconvenience of voting by making voting on Election Day less rivalrous with other activities. Do vote centers produce shorter wait times to vote, more qualified poll workers to assist voters with voting equipment, and voting places more central to where voters work, shop, and travel? If voters, especially infrequent voters, have a more positive voting experience at vote centers, does this lead to more frequent voting? These are questions that need to be pursued in future research about vote centers and the administration of elections in general.

\footnotetext{
${ }^{5}$ Richey (2008) reports that turnout increased in Oregon's allmail elections with higher turnout elections. All-mail elections differ from absentee mail-in balloting in that ballots are sent to all voters in Oregon. Voters in states with absentee mail-in voting must request a mail-in ballot.
} 


\section{REFERENCES}

Alvarez, R. Michael and Thad E. Hall. 2006. Controlling Democracy: The Principal-agent Problems in Election Administration. Policy Studies Journal 34(4): 491-510.

Angrist, Joshua and Jorn-Steffen Pischke. 2008. Mostly Harmless Econometrics: An Empiricist's Companion. Princeton, NJ: Princeton University Press.

Ansolabehere, Stephen and Charles Stewart III. 2005. Residual Votes Attributable to Technology. Journal of Politics 67: 365-389.

Arceneaux, Kevin and David W. Nickerson. 2009. Who Is Mobilized to Vote? A Re-analysis of 11 Field Experiments. American Journal of Political Science 53(1): 1-6.

Asher, Herb. 1982. The Effect of Voting Systems on Voter Participation. Presented at the annual meeting of the Midwest Political Science Association, Milwaukee, Wisconsin.

Atkeson, Lonna and Kyle Saunders. 2007. The Effect of Election Administration on Voter Confidence: A Local Matter? PS: Political Science \& Politics 40(4): 655-660.

Bendor, Jonathan, Daniel Diermeier, and Michael Ting. 2003. A Behavioral Model of Voter Turnout. American Political Science Review 97: 261-280.

Brady, Henry and John McNulty. 2011. Turning Out to Vote: The Costs of Finding and Getting to the Polling Place. American Political Science Review 105(1): 115-134.

Collin County Observer. 2011. Collin County Commissioners Court Hears Complaints about Long Voter Lines, <http:// www.baumbach.org/b2evolution/blogs/index.php/2011/01/ $12 / \mathrm{p} 1765>$.

Dyck, Joshua and James Gimpel. 2005. Distance, Turnout, and the Convenience of Voting. Social Science Quarterly 86(3): 531-548.

Fowler, James H. 2006. Habitual Voting and Behavioral Turnout. The Journal of Politics 68: 335-344.

Gerber, Alan, Donald P. Green, and Ron Shachar. 2003. Voting May Be Habit-Forming: Evidence from a Randomized Field Experiment. American Journal of Political Science 47: 540-550.

Gimpel, James and Jason Schuknecht. 2003. Political Participation and the Accessibility of the Ballot Box. Political Geography 22(4): 471-488.

Gosnell, Harold F. 1927. Getting out the Vote: An Experiment in the Stimulation of Voting. Chicago: The University of Chicago Press.

Haspel, Moshe and H. Gibbs Knotts. 2005. Location, Location, Location: Precinct Placement and the Costs of Voting. Journal of Politics 67(2): 560-573.
Hall, Thad, Quin Monson, and Kelley Patterson. 2009. The Human Dimension of Elections: How Poll Workers Shape Public Confidence in Elections. Political Research Quarterly 62(3): 507-522.

Highton, Benjamin. 2000. Residential Mobility, Community Mobility, and Electoral Participation. Political Behavior 22(2): 109-122.

Juenke, Eric Gonzalez and Julie Marie Shepherd. 2008. Vote Centers and Voter Turnout. In Bruce Cain, Todd Donovan, and Caroline Tolbert (eds.), Democracy in the States. Washington D.C.: Brookings Institution Press. 55-67.

Karp, Jeffrey and Susan Banducci. 2000. Going Postal: How All-Mail Elections Influence Turnout. Political Behavior 22(3): 223-239.

Kousser, Thad and Megan Mullin. 2007. Does Voting by Mail Increase Participation? Using Matching to Analyze a Natural Experiment. Political Analysis 15: 428-445.

Magleby, David. 1987. Participation in Mail Ballot Elections. Western Political Quarterly 40(1): 79-91.

Malhotra, Neil, Melissa R. Michelson, Todd Rogers, and Ali Adam Valenzuela. 2011. Text Messages as Mobilization Tools: The Conditional Effect of Habitual Voting and Election Salience. American Politics Researcher 39(4): 664-681.

Merriam, Charles and Harold Gosnell. 1924. Non-Voting. Chicago: University of Chicago Press.

Merrit, George. 2006. City Asked for Pollbook Software. Denver Post Dec: B1.

Richey, Sean. 2008. Voting by Mail: Political Participation and Institutional Reform in Oregon. Social Science Quarterly 39(4): 902-15.

Stein, Robert M. and Greg Vonnahme. 2008. Engaging the Unengaged Voter: Vote Centers and Voter Turnout. Journal of Politics. 70: 1-11.

Stein, Robert M., Greg Vonnahme, Michael Byrne, and Daniel Wallach. 2008. Voting Technology, Election Administration, and Voter Performance. Election Law Journal 7: 123-135.

Address correspondence to: Robert M. Stein Department of Political Science Rice University 6000 S. Main Houston, TX 77251 E-mail: stein@rice.edu 


\section{APPENDIX}

\section{Placebo test for Colorado and Texas}

In this placebo test we evaluate whether Election Day Vote Centers (EDVCs) are related to voter turnout in 2004. This provides one means of formally assessing whether an unobserved variable can fully account for the relationship between vote centers and turnout discussed in the main text of the article. To conduct this analysis, we coded a variable for voter turnout in 2004. In so doing we dropped Larimer County from the analysis since they implemented vote centers in 2004. This variable is subject to a non-trivial amount of measurement error. Since the voter file was obtained following the 2008 election (January 2009), some individuals that were on the voter rolls in 2004 will not be in the 2008 data. Additionally, we dropped anyone that updated their registration information after 2004 to eliminate the possibility that a voter in the analysis might have moved from one county to another (i.e., we only observe their county of residence in 2008, which might not have been their county of residence in 2004). This was, unfortunately, not possible in Texas as the voter file data did not include a registration date. The data from the three Texas counties introduced additional limitations as the vote history variable only went back to 2004, so there was no data on prior turnout that we could include in the placebo test.

The results of the placebo test are shown in Table A1 for Colorado and Texas. First differences are shown in Table A2 (there was no vote history variable or interaction in the Texas data). These results show a weak to negative association between placebo-vote centers and turnout. The association in Texas is negative; in Colorado there is a positive association and the substantive relationship is relatively weak. While the analysis by no means obviates the concern about unobserved variables, it does weaken the hypothetical counter-claim that the results presented in the main body of the article are attributable to an unobserved factor.

\section{Standard errors clustered by county}

The following three tables show logit estimates with standard errors clustered by county and different subsets of the control variables.
Table A1. Logit Estimates

for Placebo-Vote Centers

\begin{tabular}{lcc}
\hline & $C O$ & $T X$ \\
\hline Placebo-EDVC & $0.098^{* * *}$ & -0.050 \\
& $(0.008)$ & \\
Age & $-0.002^{* * *}$ & 0.037 \\
& $(0.000)$ & \\
Female & $0.052^{* * *}$ & \\
& $(0.005)$ & 0.683 \\
Partisan & $0.186^{* * *}$ & \\
& $(0.005)$ & \\
Habit & $0.141^{* * *}$ & \\
& $(0.001)$ & -0.896 \\
Habit $\times$ Placebo & $0.021^{* * * *}$ & \\
& $(0.002)$ & 211,864 \\
Contant & $1.450^{* * * *}$ & \\
& $(0.009)$ & \\
N $=$ & $1,811,932$ & \\
\hline
\end{tabular}

Table A2. First Differences for Placebo-Vote Centers

\begin{tabular}{lcc}
\hline Habit & CO & TX \\
\hline 0 & 0.007 & \\
1 & 0.009 & \\
2 & 0.010 & \\
3 & 0.012 & \\
4 & 0.013 & -0.010 \\
All & 0.012 & \\
\hline
\end{tabular}

Table A3. Models with Standard Errors Clustered by County from the Texas 2008 Data

\begin{tabular}{lccccc}
\hline & $(1)$ & $(2)$ & $(3)$ & $(4)$ & $(5)$ \\
\hline EDVC & 0.907 & 0.945 & 0.947 & 0.861 & 0.850 \\
& $(0.897)$ & $(0.928)$ & $(0.936)$ & $(1.387)$ & $(1.388)$ \\
Age & & & -0.003 & & -0.003 \\
& & & $(0.004)$ & & $(0.004)$ \\
Major Party & & & 0.580 & & 0.591 \\
& & & $(0.788)$ & & $(0.806)$ \\
Vote History & & 0.216 & 0.191 & 0.200 & 0.172 \\
& & $(0.151)$ & $(0.172)$ & $(0.230)$ & $(0.248)$ \\
EDVC $\times$ & & & & 0.043 & 0.050 \\
Vote History & & & & $(0.230)$ & $(0.228)$ \\
Constant & 0.396 & -0.111 & 0.023 & -0.077 & 0.064 \\
& $(0.897)$ & $(1.210)$ & $(1.245)$ & $(1.387)$ & $(1.415)$ \\
Observations & 19884 & 19884 & 19884 & 19884 & 19884 \\
Counties & 3 & 3 & 3 & 3 & 3 \\
\hline
\end{tabular}

Clustered standard errors in parentheses. 
Table A4. Models with Standard Errors Clustered by County from the Colorado 2008 Data

\begin{tabular}{|c|c|c|c|c|c|}
\hline & (1) & (2) & (3) & (4) & (5) \\
\hline EDVC & $\begin{array}{c}0.104 \\
(0.111)\end{array}$ & $\begin{array}{c}0.115 \\
(0.105)\end{array}$ & $\begin{array}{c}0.116 \\
(0.105)\end{array}$ & $\begin{array}{c}0.108 \\
(0.086)\end{array}$ & $\begin{array}{c}0.109 \\
(0.086)\end{array}$ \\
\hline Age & & & $\begin{array}{c}0.001 \\
(0.002)\end{array}$ & & $\begin{array}{c}0.001 \\
(0.002)\end{array}$ \\
\hline Female & & & $\begin{array}{l}0.214^{* * * *} \\
(0.028)\end{array}$ & & $\begin{array}{l}0.214 * * * \\
(0.028)\end{array}$ \\
\hline Major Party & & & $\begin{array}{l}0.322 * * * \\
(0.036)\end{array}$ & & $\begin{array}{l}0.322 * * * \\
(0.036)\end{array}$ \\
\hline Vote History & & $\begin{array}{l}0.191 * * * \\
(0.014)\end{array}$ & $\begin{array}{l}0.181 * * * \\
(0.012)\end{array}$ & $\begin{array}{l}0.189 * * * \\
(0.023)\end{array}$ & $\begin{array}{l}0.179 * * * \\
(0.021)\end{array}$ \\
\hline EDVC $\times$ Vote History & & & & $\begin{array}{c}0.003 \\
(0.027)\end{array}$ & $\begin{array}{c}0.003 \\
(0.026)\end{array}$ \\
\hline Constant & $\begin{array}{l}1.020 * * * \\
(0.095)\end{array}$ & $\begin{array}{l}0.371 * * * \\
(0.078)\end{array}$ & $\begin{array}{c}0.064 \\
(0.079)\end{array}$ & $\begin{array}{l}0.375^{* * * *} \\
(0.071)\end{array}$ & $\begin{array}{c}0.067 \\
(0.089)\end{array}$ \\
\hline $\begin{array}{l}\text { Observations } \\
\text { Counties }\end{array}$ & $\begin{array}{c}19552 \\
64\end{array}$ & $\begin{array}{c}19552 \\
64\end{array}$ & $\begin{array}{c}19552 \\
64\end{array}$ & $\begin{array}{c}19552 \\
64\end{array}$ & $\begin{array}{c}19552 \\
64\end{array}$ \\
\hline
\end{tabular}

Clustered standard errors in parentheses.

$* * * p<0.01, * * p<0.05, * p<0.1$.

Table A5. Models with Standard Errors Clustered by County from the Colorado 2006 Data

\begin{tabular}{|c|c|c|c|c|c|c|}
\hline & (1) & $(2)$ & (3) & (4) & (5) & (6) \\
\hline EDVC & $\begin{array}{r}-0.074 \\
(0.117)\end{array}$ & $\begin{array}{c}-0.105 \\
(0.129)\end{array}$ & $\begin{array}{c}-0.106 \\
(0.125)\end{array}$ & $\begin{array}{c}0.065 \\
(0.099)\end{array}$ & $\begin{array}{c}0.063 \\
(0.100)\end{array}$ & $\begin{array}{c}0.209^{*} \\
(0.123)\end{array}$ \\
\hline Age & & & $\begin{array}{l}0.012 * * * \\
(0.001)\end{array}$ & & $\begin{array}{l}0.012 \text { *** } \\
(0.001)\end{array}$ & $\begin{array}{l}0.012 * * * \\
(0.002)\end{array}$ \\
\hline Female & & & $\begin{array}{c}-0.031 \\
(0.049)\end{array}$ & & $\begin{array}{c}-0.031 \\
(0.049)\end{array}$ & $\begin{array}{c}-0.034 \\
(0.048)\end{array}$ \\
\hline Major Party & & & $\begin{array}{l}0.218 * * * \\
(0.033)\end{array}$ & & $\begin{array}{l}0.218^{* * * *} \\
(0.034)\end{array}$ & $\begin{array}{l}0.226 * * * \\
(0.034)\end{array}$ \\
\hline Vote History & & $\begin{array}{l}0.293^{* * *} \\
(0.021)\end{array}$ & $\begin{array}{l}0.269 * * * \\
(0.019)\end{array}$ & $\begin{array}{l}0.329 * * * \\
(0.018)\end{array}$ & $\begin{array}{l}0.304 * * * \\
(0.017)\end{array}$ & $\begin{array}{l}0.304 * * * \\
(0.017)\end{array}$ \\
\hline EDVC $\times$ Vote History & & & & $\begin{array}{c}-0.065^{* *} \\
(0.030)\end{array}$ & $\begin{array}{c}-0.064 * * \\
(0.028)\end{array}$ & $\begin{array}{c}-0.064 * * \\
(0.028)\end{array}$ \\
\hline Denver/Douglas & & & & & & $\begin{array}{c}-0.374 * * \\
(0.174)\end{array}$ \\
\hline Constant & $\begin{array}{c}-0.165 * * \\
(0.072)\end{array}$ & $\begin{array}{c}-1.191 * * * \\
(0.073)\end{array}$ & $\begin{array}{c}-1.758 * * * \\
(0.098)\end{array}$ & $\begin{array}{c}-1.281 * * * \\
(0.071)\end{array}$ & $\begin{array}{c}-1.845^{* * *} \\
(0.077)\end{array}$ & $\begin{array}{c}-1.839 * * * \\
(0.082)\end{array}$ \\
\hline Observations & 19554 & 19554 & 19554 & 19554 & 19554 & 19554 \\
\hline Counties & 64 & 64 & 64 & 64 & 64 & 64 \\
\hline
\end{tabular}

Clustered standard errors in parentheses.

$* * * p<0.01, * * p<0.05, * p<0.1$. 